\title{
Water regimes of rice fields
}

\author{
Satbay Nurjanov ${ }^{*}$ \\ Tashkent Institute of Irrigation and Agricultural Mechanization Engineers, 100000, Kari Niyazi st. 39, \\ Tashkent, Uzbekistan
}

\begin{abstract}
The article is a review work, periodic moistening - a layer of water is absent throughout the entire growing season of rice, optimum soil moisture is created through periodic irrigation. Mostly applied permanent and shortened flooding. The most promising is the water regime with shortened flooding. Depending on the method of sowing, debris from the rice field by grasslands and soil salinization, there are various options for this mode. Rice plant, like any other, imposes different requirements for water in different phases of the growing season. The best medium for rice in the period of germination and in the phase of emergence is a moist soil. To obtain seedlings on highly saline soils with a close level of saline groundwater, the most favorable is a small layer of water, which is periodically replaced.
\end{abstract}

\section{Introduction}

The chronic shortage of food and agricultural raw materials strictly poses the problem of accelerated, steady growth of the yield of all agricultural crops, including rice, to the agriculture of the Republic of Karakalpakstan. The Republic of Karakalpakstan is the largest rice-growing region in Uzbekistan, almost entirely located in the environmental disaster zone of the Aral Sea region. The soil and climatic conditions of the region are quite favorable for rice cultivation, but now in most areas there is a limitation of natural resources, as well as the disruption of many natural ecological processes caused by rash anthropogenic activities. The most important reserve for increasing the yield of rice in the Aral Sea region is the development and implementation of zonal progressive farming systems that ensure the improvement of the soil-ecological conditions for growing crops. Accelerated development of rice growing in Karakalpakstan should be based on the transition to intensive resource-saving technologies. For this, it is necessary to have scientifically grounded recommendations that allow a set of basic natural factors to be maintained and the anthropogenic impact on the agroecosystem.[1-2].

Rice is a unique crop in terms of its ability to grow and produce high yields in conditions of strong soil saturation with water and even when creating a layer of water.

In the practice of rice sowing, the water regimes used in the soils of rice fields are very diverse, but they can be reduced to four main types:

1. Permanent flooding - the water layer on the field is maintained from sowing to the start of harvesting.

\footnotetext{
* Corresponding author: shamshodbekjon@mail.ru
} 
2. Shortened flooding - during the period of seed germination, the soil is kept wet, and a layer of water is created from the moment of full germination and remains until the beginning of the ripeness of the rice.

3. Intermittent flooding - in some periods there is no layer of water, and the soil is kept wet between the irrigations.

4. Periodic moistening - the water layer is absent throughout the entire growing season of rice, optimum soil moisture is created by periodic watering.In the presence of a layer of water, seeds germinate worse, which is one of the causes of thinning of crops, especially in conditions of re-cooling during early sowing. Simultaneously with the death of the primary root system, the tops of the leaves begin to dry out. If by this time the secondary root system had not yet formed, the plants die. The secondary root system (from 3 leaves to the end of tillering) is more tolerant to excess salt, and plants that have developed it well, in most cases, are preserved with progressive salinization, under conditions of a certain water regime. The primary root system from the excess salt in the soil dies completely $[1,3]$.

\section{Research methods}

Field experiments were conducted on the territory of the experimental base of the Karakalpak branch of the Uzbek Scientific Research Institute of the Rice of the Nuku District of the Republic of Karakalpakstan.

The soils of the experimental plot belong to irrigated meadow-alluvial varieties. By mechanical medium loamy.

At the experimental site, the size of the dense residue in a layer of $0-50 \mathrm{~cm}$ was $0.44-$ $1.52 \%$, chlorine ion to $0.060 \%$, sulfate ion $0.442 \%$, the soil was moderately saline in chloride-sulfate type. [1, 3-5].

Groundwater occurs during the non-growing season at a depth of $1.29 \mathrm{~m}$ from the soil surface with a salinity of $7.5 \mathrm{~g} / 1$ for a dense residue.

From the water-physical properties of the soil, the soil moisture was determined by the gravimetric method, the smallest water capacity by the honeycomb of the bay area. The bulk density of the soil was determined by the horizons of $0-10 \mathrm{~cm} ; 10-30 \mathrm{~cm} ; 30-50 \mathrm{~cm}$; $50-70 \mathrm{~cm} ; 70-90 \mathrm{~cm}$ in three places of each repetition before the start of pre-sowing treatments of the soil, cylinder- $10.5 \mathrm{~cm}$ in diameter.

Accounting of the incoming and drainage water was carried out using the Chumakov table, water flow through round tubes. The determination of the elements of the water balance was carried out according to the VB method. Zaitsev (1975) on evaporator vessels. The degree of mineralization of irrigation, drainage and groundwater was determined after 5 days[25].

When conducting the experiment, they were guided by the methodological guidelines of the All-Union Scientific Research Institute of Rice, the Uzbek Scientific Research Institute of Rice. The experiments were conducted in 3-fold repetition with the following scheme:

Table 1. Driving experience.

\begin{tabular}{|c|c|c|}
\hline № & Options & Plotarea \\
\hline 1 & The traditional method of irrigation of rice. & 0,40 \\
\hline 2 & Intermittent watering from the tillering stage to the sweeping phase. & 0,20 \\
\hline 3 & $\begin{array}{c}\text { Intermittent watering from the tillering stage to the sweeping phase in the } \\
\text { combination of drainage waters of 2,200 m3 / gr. }\end{array}$ & 0,20 \\
\hline 4 & $\begin{array}{c}\text { Intermittent watering from the tillering stage to the sweeping phase in the } \\
\text { combination of drainage water 3400 m3 / gr. }\end{array}$ & 0,20 \\
\hline 5 & $\begin{array}{c}\text { Intermittent watering along furrows from the tillering stage to the sweeping } \\
\text { phase. }\end{array}$ & 0,20 \\
\hline
\end{tabular}


Phenological observations of the development of rice plants were carried out according to the state network.

Accounting for the density of standing plants of rice and weeds was carried out in the period of full sunrises and before harvesting in 5 places of each plot in two replications, the frame size was $0.25 \mathrm{~m} 2$.

Growth was measured in the following phases: sprouting, tillering, entering the tube and ripening for 10 permanently fixed rice plants. The dynamics of filling aboveground mass was determined on 10 plants taken at the time when the height of the plants was measured. Accounting of grain yield was carried out by continuous threshing of each plot separately. The structure of the crop was determined on model sheaves by the method. Mathematical processing of the yield data was carried out according to the method of V.A. Dospekhov(1985).

\section{Research results}

Topography of the experimental site. In the reporting year, before laying the field experience on the site, we carried out control leveling according to the method of $10-10 \mathrm{~m}$ squares that the soil of the test site had high aeration and saturation with nutrient elements. [1, 3-5].

Water-physical soil properties of the experimental plot. To establish the water regime, the initial soil moisture was established before sowing and the moisture capacity of the $0-50 \mathrm{~cm}$ layer was determined, the data are given in the table1.

Table 2. Water-physical soil properties of the experimental plot in the layer 0-50 cm.

\begin{tabular}{|c|c|c|c|}
\hline № & $\begin{array}{c}\text { Soil moisture before } \\
\text { sowing, \% }\end{array}$ & $\begin{array}{c}\text { Smallest water } \\
\text { capacity }\end{array}$ & $\begin{array}{c}\text { Bulk mass of the soil before } \\
\text { sowing, } \mathbf{g} / \mathbf{~ c m 3}\end{array}$ \\
\hline 1 & 19,1 & 24,2 & 1,42 \\
\hline 2 & 15,1 & 20,5 & 1,40 \\
\hline 3 & 15,9 & 20,9 & 1,38 \\
\hline 4 & 12,6 & 17,7 & 1,41 \\
\hline 5 & 14,4 & 19,3 & 1,36 \\
\hline Average & $\mathbf{1 5 , 4}$ & $\mathbf{2 0 , 5}$ & $\mathbf{1 , 3 9}$ \\
\hline
\end{tabular}

The data confirm that the percentages of the proportion of the anionic and cationic parts were within $65 \%$ to $35 \%$ with the salinity of irrigation water at $1.2 \mathrm{~g} / 1$ and the drainage water at $4.84 \mathrm{~g} / 1$.

\section{Rice irrigation regime}

On the experimental plot, depending on the rice irrigation regime being studied, the total irrigation rate varied within 16,100-22180 $\mathrm{m} 3$ / ha. At the same time, the largest amount of consumed water was noted in the control variant, which exceeded the studied variants by $3450-6080 \mathrm{~m} 3 / \mathrm{ha}$. In terms of the economy of irrigation water, it should be noted that the furrow irrigation provided a reduction of irrigation water by $6080 \mathrm{~m} 3$ / ha compared with the control variant (Table 3 ).

It should be noted here that before tillering in order to obtain amicable shoots and the best development of rice plants, watering in all studied variants was carried out by flooding checks. The furrows were irrigated only from the period of tillering until sweeping of rice plants. 
Table 3. Costs of irrigation rate for options of experience $\mathrm{m}^{3} / \mathrm{gr}$

\begin{tabular}{|c|c|c|c|}
\hline \multirow{2}{*}{ № } & \multicolumn{2}{|c|}{ Irrigation water consumption } & \multirow{2}{*}{ Overall } \\
\cline { 2 - 3 } & Irrigating & Drainage & \\
\hline 1 & 22180 & - & 22180 \\
\hline 2 & 18700 & - & 18700 \\
\hline 3 & 16460 & 2200 & 18660 \\
\hline 4 & 15330 & 3400 & 18730 \\
\hline 5 & 16100 & - & 16100 \\
\hline
\end{tabular}

In intermittent water supply with a combination of irrigations with drainage water at the rate of $2,200 \mathrm{~m} 3 /$ ha, up to $5,720 \mathrm{~m} 3 /$ ha and up to $6,850 \mathrm{~m} 3 /$ ha were saved, respectively, when irrigating with drainage water at the rate of $3,400 \mathrm{~m} 3 /$ ha, compared to the control options.

As it was provided for by the working program, the supply of drainage water is carried out in the phases of tillering and at the beginning of the pipe formation of plants.

Evaporation-E, transpiration-T and vertical filtration- $\mathrm{Fb}$ were determined by the method of field vessels-evaporators V.B. Zaitsev. [3].

The essence of this technique is as follows: On the check sown with rice, four vessels are installed, two of which have no bottom. The underground part of the vessels is painted with bitumen lacquer, and the aboveground part with white paint. Vessels without bottom are pressed into the ground without disturbing its natural state. Where in spring the soil dries out strongly, this can only be done after flooding the check. Observations on vessels without bottom begin when the time comes a few days later than on vessels with a bottom. In vessels, adding water from a measuring glass, maintain a constant level. The level mark is fixed with a needle fixed on a small bracket inside the vessel. The volume of water added shows how much it has spent in this vessel during the interval between observations. In case of loss, their value is plus to the water flow rate for each of the vessels.

For water balance studies using this scheme, the GGI-3000 evaporators were also used as bottom vessels, while bottomless vessels were included in the set of rain gauges with a bottom previously removed. Application in this case, the pipette GGI greatly improves the accuracy of measurements.

Table 4. Purpose of evaporator vessels and calculation scheme

\begin{tabular}{|c|c|c|c|}
\hline \multirow{2}{*}{ Vesselnumber } & $\begin{array}{c}\text { Water consumption } \\
\text { article }\end{array}$ & \multicolumn{2}{|c|}{ Differencetestimony } \\
\cline { 3 - 4 } & & Invessels & Theresultingvalue \\
\hline 1 & $\mathrm{E}$ & $2-1$ & $\mathrm{FB}$ \\
\hline 2 & $\mathrm{E}+\mathrm{FB}$ & $4-3$ & $\mathrm{FB}$ \\
\hline 3 & $\mathrm{E}+\mathrm{T}$ & $3-1$ & $\mathrm{~T}$ \\
\hline 4 & $\mathrm{E}+\mathrm{T}+\mathrm{FB}$ & $4-2$ & $\mathrm{~T}$ \\
\hline
\end{tabular}

Vessels 2 and 4 have no bottom. In vessels 3 and 4, rice is sown. By the beginning of tillering, part of the plants that have arisen in the vessel for thinning are pulled or, on the contrary, planted so that the number of plants per unit area in them and on the check coincide.

By calculating the vessel numbers, as shown in Table 4, all values are determined. The main indicators are the readings of vessel 4 , which serves as a model of a check without lateral outflow of water. The proposed method does not take into account condensation of water vapor (loss of growth) in the cold night hours. But condensation does occur in the rice field and in the evaporators, so the final results are not distorted. To create shading with free water, surfaces in vessels 2 and 4 that meet the conditions occurring on the check, rice is planted around them more often than usual. 
The indicators for calculating the elements of the water balance show that, during the growing season, despite the differences in the water supply schemes, the total number of components of the water balance for the variants of the experiment was in the same amount.

It follows that about $2900-2720 \mathrm{~m} 3$ / ha were spent for moisture saturation in the soil, 4500$4100 \mathrm{~m} 3$ / ha for evaporation, 5650-5150m3 / ha for transpiration and 7650-4380 $\mathrm{m} 3$ / ha for filtration. These data suggest that the soil of the experimental plot, located in the inflow area due to good performance of the DPT, ensured the flow of water from the aeration zone, which, in ameliorative terms, created the best condition for soil desalinization from deep horizons.

From the indicators of these vessels of the evaporators VB Zaitsev, it follows that in the control variant the evaporation from the water surface was at the level of $4500 \mathrm{~m} 3 / \mathrm{ha}$, at the level of $4430 \mathrm{~m} 3$ / ha (Table 4). In general, during the growing season, the highest rates are observed on dates 20.VI-10.VII, which corresponds to the period of mass tillering of rice.

The data obtained is due to the fact that during this period it is necessary to maintain a relatively high level of water in the checks for the destruction of weeds, especially the river grass. In addition, the initial thaws accompanying wind reinforcements cause turbulence of the air mass, which, as is known, accelerates the processes of moisture movement in the environment of plants. It follows that the indicators of total water consumption, depending on the studied options, have a different value.

In general, the growth and development of rice shows that the tested options are somewhat disadvantaged compared to the control. Therefore, in the following it should be noted on this special attention. At the same time, in our opinion, intermittent irrigation methods, by their nature, cause drastic changes in the temperature regime of water in the checks, which is not a desirable issue, especially during the period of rice biomass growth.

Table5. Biometric indicators of rice yield

\begin{tabular}{|c|c|c|c|c|c|c|}
\hline № & $\begin{array}{c}\text { quantity of } \\
\text { production } \\
\text { of stalks pcs } \\
/ \mathbf{~ m}^{\mathbf{2}}\end{array}$ & $\begin{array}{c}\text { number of } \\
\text { grains } \\
\text { performed, } \\
\text { pcs }\end{array}$ & $\begin{array}{c}\text { Emptygrai } \\
\mathbf{n} \\
\mathbf{\%}\end{array}$ & $\begin{array}{c}\text { Grain } \\
\text { mass } \\
\text { one } \\
\text { panicle, g }\end{array}$ & $\begin{array}{c}\text { weight 1000 } \\
\text { Grains g }\end{array}$ & $\begin{array}{c}\text { Productivit } \\
\mathbf{y} \\
\text { centnersper } \\
\text { hectare }\end{array}$ \\
\hline 1 & 182 & 114 & 18,7 & 3,2 & 28,0 & 54,5 \\
\hline 2 & 175 & 102 & 18,7 & 2,9 & 28,4 & 48,6 \\
\hline 3 & 181 & 91 & 19,2 & 2,6 & 28,0 & 43,9 \\
\hline 4 & 173 & 94 & 20,0 & 2,6 & 28,5 & 41,4 \\
\hline 5 & 162 & 87 & 19,7 & 2,5 & 28,5 & 38,8 \\
\hline
\end{tabular}

In accordance with the growth and development of the accumulated biometric indicators of rice, which are reflected in table 5. From this it follows that the number of productive stems varied from 162 to 182 pcs per square meter. In this case, the largest value is noted in the control, and the smallest in the variant for irrigation furrows. [4-5,7].

Empty grain fluctuated at the level of $18.7-20.0 \%$, and the mass of grain of one panicle was about 2.5-3.2 g. Thus, the tested variants are significantly reflected in the accumulations of the number of productive stems and the mass of grain of one panicle.

\section{References}

1. Gutova O. A., Sheudjen A. Kh.,KhurumKh. D. Soil processes in the rice fields of the Kuban // Proceedings of the Kuban State Agrarian University. 2013. № 44. pp. 59-61. 
2. Zelenskiy P. G., Isupova Y. A., Zelensky A. G., Shatalov M. V. Experience of using the fertilizer "Poligro" when growing rice // Rice production. 2013. № 2 (23). pp. 5963.

3. ZaycevV.B. Rice irrigation system. M., 1975 pp72-143

4. KizinekC. V., BurunovA. N. Efficiency of application of complex mineral fertilizers with trace elements on meadow chernozem soils in rice cultivation // XXI century: past results and present problems plus. 2012. № 02 (06). pp. 246-251.

5. Xachmamuk P. N. Effects of fertilizer "Bioplant Flora" on the content of macronutrients in the aboveground organs of rice plants // Enthusiasts of Agrarian Science: Coll. Art. Based on conf. Krasnodar: KGAU, 2014. pp. 44-45.

6. AbduraxmanovA. A., RamazonovA. Agromeliorative techniques for increasing the fertility of the gray-earth - meadow soils of Central Fergana // Proceedings of the Republican meeting on the problems of increasing the fertility of irrigated soils in Uzbekistan. Tashkent 2002. pp. 80-88.

7. UmurzakovU. P., IbragimovA. G., DurmanovA. Sh. The development of the organizational and economic mechanism and the development of scientific, methodological and theoretical foundations for improving the efficiency of the rice growing industry to ensure the food security of the country // Science and Practice Bulletin. 2017. №11 (24). pp. 103-118.

8. Durmanov A., Umarov S. Economic-mathematical modeling of optimization production of agricultural production // Asia Pacific Journal of Research in Business Management. 2018. No 9(6), pp. 10-21.

9. Tulaboev A. Blended learning approach with web 2.0 tools // 2013 International Conference on Research and Innovation in Information Systems (ICRIIS), Kuala Lumpur, 2013. pp. 118-122. doi: 10.1109/ICRIIS.2013.6716695

10. Tulaboev A., Oxley A. A case study on using web 2.0 social networking tools in higher education // In Computer \& Information Science (ICCIS), 2012 International Conference on. 2012. No 1. pp. 84-88.

11. Tulaboev A., Oxley A. A pilot study in using web 2.0 to aid academic writing skills // Open Systems (ICOS). 2010. pp. 45-50.

12. Muradov R. A. Water use in conditions of deficit of irrigation water // Bulletin of the Tashkent State Technical University. 2010. No 1-2, pp. 164-168.

13. Muradov R. A. Some issues of effective land use in the WUA in case of water resources shortage // Agrarian Science for Agriculture. Proceeding IX international.scientific-practical conference. Barnaul, Altai State University, 2014. pp. 460-462. (in Russian).

14. Muradov R. A., Khozhiev A. A. Optimal solution of washing norms in case of deficit of irrigation water // Agro ilm. 2017. No 5, pp. 83-84.

15. Ibragimov A. G., Durmanov A. S. Issues of the development of competitiveness and the prospects of specialization in rice farms // SAARJ Journal on Banking \& Insurance Research, 2017. No 6(5), pp. 14-19. doi:10.5958/2319-1422.2017.00021.2.

16. DurmanovA. Sh.,XidirovaM. X. Меры по увеличению объемов экспорта плодоовощной продукции // Economics. 2017. № 9(30), pp. 30-34.

17. Khamidov A. A., Khudaykulov S. I., Makhmudov I. E. Hydromechanics. Tashkent. FAN. 2008. pp. 140.

18. Umarov S. R. Innovative development and main directions of water management.Economy and Innovative Technologies, 2017. No 1. Available at: https://goo.gl/eEHSJK. (in Uzbek).

19. SommerR, GlazirinaM., YuldashevT., OtarovA., IbraevaM., MartynovaL., BekenovM., KholovB., IbragimovN., KobilovR., KaraevS., SultonovM., KhasanovaF., EsanbekovM., MavlyanovD., IsaevS., Abdurahimov S., Ikramov R., ShezdyukovaL., 
Pauw de E.-Impact of climate change on wheat productivity in Central Asia]. Agronomy Jornal. The USA American Society of Agronomy. America 2013-year. pp 78-99.

20. Isaev S.X.,Radjabov T.T., Dolidudko A.A.- Influence of inorganic fertilizers on cotton crop yield in saline soils//Bulletin of Science and Practice] 2018. Tashkent, 4 No7, pp 160-165.

21. Isaev S.X.,Axmedov SH., Mardiyev SH.- Cotton crop yield on takyr soils under the influence of wind erosion//Bulletin of Science and Practice] 2018. Tashkent, 4 No7, pp 160-165.

22. Isaev S.H., Jumanov A.-Mathematical modelling of the processes of accumulation of precipitation and irrigation of mountain and piedmont lands//Bulletin of Science and Practice] 2018. Tashkent, 4 No7, pp 160-165.

23. Isaev S.H., Khaidov B.- Drainage water use for cotton-plant irrigation//Bulletin of Science and Practice]. Tashkent. 2018 year. 4 No 9, pp 109-113.

24. Matyakubov B.SH. Efficient use of water in the Khorezm Oasis International journal of innovations in engineering research and technology [IJIERT], ISSN: 2394-3696, VOLUME 5, ISSUE 11, Nov.-2018., pp 44-49.

25. Bouman, B. A. M., \& Tuong, T. P. (2001). Field water management to save water and increase its productivity in irrigated lowland rice. Agricultural water management, 49(1), 11-30. 